\title{
ESPACIO Y HOMBRE EN LA ESPAÑA NORTEÑA EN LA EDAD MEDIA*
}

\author{
José Ángel Garcia de Cortázar \\ Universidad de Cantabria
}

En el arranque de estas páginas, la conocida idea de Marc Bloch: "los campos sin señor son campos sin historia». Los espacios sin señor son espacios sin historia podríamos remedar nosotros al internarnos por unos territorios, los que van del Deva astur-cántabro al Bidasoa y del Cantábrico al Ebro, que con tanta morosidad se han incorporado a nuestro conocimiento histórico. ¿Porque no tuvieron señor hasta muy tarde o porque los señores que tuvieron median su dominio y sus exigencias sobre el espacio con categorías distintas de los hombres que, a la postre, iban a hacer su historia, esto es, a tratar de comprenderlos, de adoctrinarlos, de aculturarlos? Porque, en definitiva, lo que se plantea en un trabajo con este título es la observación de los comportamientos, de los intercambios entre naturaleza (el espacio) y cultura (el hombre) de una determinada área geográfica. $Y$ de ese seguimiento lo que surge es una historia que tratará de poner de relieve, sucesivamente, tres grandes capítulos: la variedad de espacios; la articulación de los espacios; la jerarquización de los espacios. En cada uno de ellos, los hombres tienen un papel crecientemente protagonista. Al frente de ellos, de forma cada vez más ostensible, los señores. Gracias a ellos, también nuestros espacios tienen historia.

\section{VARIEDAD: LA EXTREMA DIVERSIDAD DE LOS ÉSPACIOS NORTEÑOS}

Nada más seguro que cinco imágenes documentales para dar cuenta de esta variedad. Y nada más expresivo que presentarlas en una secuencia cronológicamente inversa a como realmente se produjeron. 
Primera imagen. El 26 de mayo de 1480, los Reyes Católicos se dirigían, desde Toledo, a las autoridades de las villas de «Santander e Sant Vicente de la Barquera e Laredo e Castro de Ordiales, e todas las otras villas e valles, concejos, merindades, filigresías, que son en las merindades de Castylla Vieja e Trasmiera e Asturias de Santyllana con el marquesado de Santyllana e Liebana e Pernia e las merindades de Campos e los otros lugares así realengos como abadengos, behetrías e señoríos que fasen juntas e ayuntamientos, asi de esas hermandades como otros qualesquier, ...» a fin de reclamar su ayuda para poner en pie una armada debidamente aparejada. La esperanza de ver atendida su solicitud la basan en que, "desde tiempo ynmemorial a esta parte, el reyno de Galicia, el principado de Asturias e el condado de Vyscaya a la leal provinçia de Guipuscoa con la çiubdad de Vytoria e Alava e las Encartaciones e las otras villas de la costa de la mar siempre fesieron sennalados servicios a los reyes que fueron de Castilla y León...». Como se ve, el texto no tiene desperdicio para nuestro objetivo. En escasas palabras da la medida exacta de la multiplicidad de espacios que, a fines del siglo XV, eran visibles en el Norte peninsular.

De su simple enumeración no parece temerario deducir ya algunas consecuencias. Al menos, en dos órdenes de cosas. El primero, la variedad de espacios socio-jurídicos; bien por la calidad de su titular, lo que los ordena en realengos, abadengos, señoríos y behetrías; bien por la red de relaciones administrativas, que los organiza en merindades, valles, concejos, feligresías, de un lado, y en ciudades, villas y lugares, de otro. El segundo, la percepción de cada uno de los espacios mayores y el grado de su individualización. A este respecto, es fácil señalar un hecho llamativo. Desde la óptica de los Reyes Católicos, esto es, de la administración territorial a fines del siglo XV, existen, dentro de ese espacio, una serie de unidades espaciales. La provincia de Guipúzcoa, que aparece como un todo unitario. El condado de Vizcaya, junto al cual, aunque, para entonces, formaban parte ya del Señorío de Vizcaya, se señalan las Encartaciones como espacio dotado de personalidad. Un territorio no calificado, el de Álava, dentro del cual se reconoce preeminencia a la ciudad de Vitoria; $y$, por fin, en lo que hoy es la comunidad autónoma de Cantabria, un mosaico de territorios; sin que ningún nombre englobador los agrupe, el mero hecho de que aparezcan juntos parece abonar la idea de una cierta unidad por encima de su diversidad. Dentro de ella, dos subconjuntos significativos: las Cuatro Villas de la Costa y las merindades de Asturias de Santillana Trasmiera, Liébana, Campoo.

Segunda imagen. Escenario: las Cortes de Gualajara de 1390, en vísperas de la muerte del rey Juan I de Castilla. En ellas, los prelados del reino 
se quejan al monarca de ciertos daños que les inflingen los nobles. Al enumerar los, comienzan por el territorio que nos ocupa. En efecto, los obispos se consideran «agraviados que en el obispado de Calahorra, do era la tierra de Vizcaya e de Alava e de Guipuzcoa, e otrosi en el Obispado de Burgos (dentro del cual, podriamos añadir nosotros, se hallaban las tierras de las Cuatro Villas y las merindades antes enumeradas), eran muchas iglesias que los diezmos della levaba el Señor de Vizcaya e otros muchos caballeros e fijosdalgo, e que era contra todo derecho, ca ningun diezmo non lo podia levar lego... E otrosí eran muchas iglesias en Guipúzcoa de las cuales levaban el diezmo legos; e que el obispo de Pamplona, en cuya juridicion son, diera aquellas iglesias a clérigos que oviesen sus beneficios en ellas, e que las sirviesen; e que ge lo non consintieran los legos tenedores de las dichas iglesias, antes hacian sus estatutos e ordenanzas que matasen a qualesquier que tales cartas troxiesen". Si las quejas episcopales dejan ver rasgos de una sociedad arcaica, la réplica de los nobles, que se debió probablemente a un alavés ilustre, el canciller Pedro López de Ayala, refrenda definitivamente esa impresión.

Tercera imagen. Tras la político-administrativa de 1480 y la social de 1390 , la económica que, unos doscientos años antes de esta fecha, recogía el documento de los falsos «Votos de San Millán». También en él la percepción del espacio reconoce una diferencia en el mismo sentido que advertíamos en el de 1480. De un lado, Álava, dividida, según el texto, en alfoces, dentro de cada uno de los cuales una serie de villae, aldeas, sevían de asiento a las domus que habian de entregar una reja de hierro al monasterio. Junto a ella, Guipúzcoa compartimentada en otra serie de alfoces, cada uno de los cuales debía aportar un buey. El mismo compromiso tenían los alfoces de Vizcaya. De ésta se distinguia el territorio de las Encartaciones, que, aunque no con ese nombre, lo hace con el de algunos de sus valles: Salcedo, Sopuerta, Carranza, distribuidos en alfoces con sus correspondientes villae, de las que cada casa debía aportar singulas libras de cera. Por fin, el territorio al Oeste de las Encartaciones, esto es, el de la actual región de Cantabria, aparece distribuido en: valles (Iguña, Buelna, Toranzo); espacios sin calificación, compartimentados en alfoces (Guriezo, Sámano, Campoo, Valderredible) o no compartimentados (Asón, Soba, Ruesga); y núcleos concretos como los de Colindres y Laredo. De cada uno de ellos el monasterio de San Millán reclamaba un producto: cera, pescado, aceite de pescado, respectivamente. En su conjunto, el documento de los falsos "Votos de San Millán" ponía de relieve, fundamentalmente, dos cosas. De un lado, la unanimidad en la percepción del espacio en distintas unidades, cada una de ellas, con un valor diferente. De otro, la universalización del vocablo «alfoz» para deno- 
minar el territorio en que se subdividen unidades geográficas o geográficosociales más amplias o en que se inscriben unidades locales más reducidas. De esa forma, valle, alfoz, villa, domus parece la secuencia espacial que de mayor a menor tamaño nos recuerda el documento.

Cuarta imagen. Unos cien años antes de que el monje emilianense amañara el texto anterior, una serie de documentos de mediados del siglo X| se pronuncia sobre la división eclesiástica de nuestro espacio. De Este a Oeste del mismo, cinco sedes se lo reparten: Bayona, Pamplona, Álava, Burgos y Oviedo. No vamos a entrar en las vicisitudes concretas experimentadas por ellas, precisamente, en la segunda mitad del siglo $\mathrm{XI}$, en que cristalizan los perfiles geográficos de esta red episcopal. Bástenos señalar tres hechos importantes. Uno: contrariamente a la práctica de la Iglesia, una de las sedes, la de Álava, no lleva el nombre de una localidad sino la de un territorio. Dos: los límites entre cada uno de los obispados no sólo recuerdan sino que, en buena parte, reproducen las fronteras entre los pueblos prerromanos de la zona. Así, de Este a Oeste, marcan las que los romanos atribuian, sucesivamente, a vascones, várdulos, caristios, autrigones, cántabros. Y, por fin, tres: de las sedes episcopales mencionadas, sólo la de Álava radica en el territorio que estudio. Pero, por poco tiempo. Como sucederá en 1068 con la de Valpuesta, que, abarcando el territorio autrigón y parte del cántabro, se trasfiere a Burgos, en 1087, se extingue la de Álava, quedando sus territorios englobados en el obispado de Calahorra. Desde entonces, ningún obispado tendrá su sede en nuestro espacio.

Quinta y última imagen. A fines del siglo IX, la corte ovetense del rey Alfonso III se propone realzar las glorias de su monarca. Para ello, nada parece más oportuno que empalmar su reinado con el de los reyes visigodos. Al hacerlo, el cronista se detiene, especialmente, en las actividades de dos predecesores gloriosos. Alfonso Il y Alfonso I. Si a aquél correspondió el restablecimiento de un ordo gothorum, al reinado de Alfonso I se atribuye nada menos que el bautizo de unas cuantas de las regiones de nuestro espacio. En efecto, tras campañas de devastación por tierras del Valle del Duero, Alfonso 1 llevó a los cristianos de la meseta a los valles cantábricos. Con ellos, a tenor de la crónica y entre otras regiones, repobló Asturias de Santillana, Liébana, Trasmiera, Sopuerta, Carranza y la primitiva Castilla. En cambio, Álava, Ayala, Orduña y Vizcaya se mantuvieron siempre en manos de sus propios habitantes. Por primera vez, nacian a la Historia los nombres de las regiones que nos ocupan. El de Guipúzcoa no lo hará hasta el año 1025. Por primera vez, también, la Crónica de Alfonso I/I nos anunciaba lo que textos posteriores nos confirmarán. La personalidad de una serie de territorios. Entre la fecha de su 
redacción y la del documento de los Reyes Católicos que proporcionaba la primera imagen, seiscientos años. $Y$, sin embargo, desde el punto de vista territorial, una impresión casi idéntica. Un reparto entre los mismos territorios nombrados a fines del siglo IX.

Mantenimiento de la personalidad de los territorios equivale a persistencia de las condiciones históricas diferenciadoras. $O$, para no caer en un estructuralismo casi geológico, cuando menos, a reiteración de condiciones históricas diferenciadoras. En su base, por tanto, una población que considera como suyo un determinado espacio y que conserva y transmite la memoria colectiva de la percepción y la valoración de ese espacio. Ello plantea, de entrada, un par de cuestiones importantes. La primera, la distinción fundamental se establece, por tanto, entre lo desierto, lo yermo, y lo poblado. La segunda tiene forma de interrogante: ¿quién nombra, quién bautiza los espacios norteños en el siglo XIII o en el IX?

La primera cuestión ha hecho ya correr si no ríos, si, al menos, riachuelos de tinta. Recordemos al respecto las opiniones encontradas de Ramón Menéndez Pidal y Caludio Sánchez Albornoz, a propósito, precisamente, de la despoblación y repoblación del Valle del Duero. La polémica tiene, como sabemos, otra versión portuguesa en los mismos términos. ¿Desertus y populatus son vocablos que tienen un contenido rigurosamente demográfico o, mayormente, organizativo? Todos entendemos el primer sentido: desertus como ausencia total de población. El segundo es menos drástico: supondría solamente una desorganización administrativa del espacio al que se aplica el adjetivo. La población con poder y facultades para organizar el espacio lo ha abandonado, dejando tras de sí grupos reducidos y dispersos de gentes poco instaladas en un territorio preciso porque su dedicación económica fundamental reside en la ganadería. Necesitan espacios para ella pero no una fijación estricta de su habitación. Para un cerealista, y no digamos para un vitivinícola, ese espacio sin cosechas anuales que recoger 0 vides que podar, esto es, sin anclajes humanos, un espacio desierto. Para un ganadero es, sin duda, un espacio con el que cuenta para mantenimiento de su riqueza semoviente. No precisa títulos de propiedad sobre él; le basta con que los demás no le discutan su derecho a aprovecharlo a través de sus rebaños.

Primera conclusión, por tanto, cada dedicación económica estimula y cada organización social propone una forma de ejercicio de derechos de propiedad o de uso del espacio. A cada una le corresponde una distinta percepción de un mismo espacio. Las propias «fórmulas inútiles» de los documentos, sobre todo, de aquéllos que se refieren por primera vez a un territorio, proporcionan ya pistas sobre su ordenación. A través de ellas, distintos in- 
vestigadores y de modo especial José María Mínguez, han sabido detectar los niveles de organización de un espacio. $Y$, junto a ellos, la percepción económica y, quizá también física, del espacio objeto de referencia documental. Así, esas villas donadas, cum montibus, pascuis, pratis, terris, vineis, ortis.... muestran, según los casos, una variada imagen. La fiabilidad de sus apreciaciones parece desprenderse del hecho de que, en el área que estudio, salvo en Liébana, el redactor del documento nunca incluye las viñas, mientras las salinas, en plural y genérico, sólo constan en aquellos lugares en que sabemos de su existencia.

Pero la distinta forma de percibir un mismo espacio no depende sólo de dedicaciones económicas diversas o de distintas formas de entender la apropiación del mismo. Aun con unanimidad absoluta en ambos criterios, las ideas que del espacio se hacen, en nuestra zona, el gran propietario y el pequeño campesino varían entre sí. Los aldeanos de los valles de la Cordillera Cantábrica aspirarán, con el tiempo, a conseguir un policultivo en cada una de sus aldeas. Tal objetivo, en cambio, no coincide necesariamente con el de los grandes dominios monásticos. Asentados ya con firmeza para fines del siglo XI, los de Leyre, San Juan de la Peña, San Millán de la Cogolla o San Salvador de Oña tendrán, a propósito del mismo espacio, distintos intereses y designios económicos. Desde luego, los de Oña y San Millán no ocultan su preferencia por hacer de esos territorios un espacio de aprovechamiento ganadero. Mucho más el de Oña que el de San Millán. Éste cuenta ya, al lado mismo del centro monástico, con los montes y pastos de la Sierra de San Lorenzo.

Población que estima como suyo un espacio; memoria colectiva que transmite la percepción del mismo, según ese procedimiento que, a veces, mencionan los mismos documentos. A falta de textos escritos, lo que causa fe y pone límites a los términos de un espacio es, precisamente, el antiquus usus a senibus testificatus. Los ancianos como depositarios de esa memoria, que, tal vez, como se puede demostrar en disposiciones del Fuero Viejo de Vizcaya de 1452, no hace sino recoger prácticas (o intereses) que no tienen más allá de treinta o cuarenta años. Ellos son los que transmiten nombres de cosas y, sobre todo, de lugares. Ellos son los que pueden, en última instancia, demostrar que el espacio presuntamente desierto sólo era un espacio mal poblado, en el sentido que, todavía para un castellano de finales del siglo XIV, tenía la expresión. Casas apartadas unas de otras, dedicación ganadera.

Si la primera cuestión que planteábamos era la percepción de un espacio y su transmisión, la segunda tiene mucho que ver con ella. ¿Quién bautiza, quién pone nombres a los distintos espacios norteños? Como principio general, parece que son los otros quienes nos ven de una u otra manera $y$, 
en consecuencia, nos bautizan. La cuestión, en nuestro caso, radica en saber cuándo «los otros» dieron nombre a esos espacios. Probablemente, las fechas variaron de uno a otro; con seguridad, los investigadores no se pondrán de acuerdo. Un ejemplo bien significativo: la polémica entre Luis MicheIena y María Lourdes Albertos. Para el primero, a un sustrato vasco o vascoide en la mayor parte de las actuales Guipúzcoa, Álava y Vizcaya, vino a sobreimponerse, en torno al 500 antes de Cristo, una población indoeuropea. Para la segunda, el proceso fue, precisamente, el contrario: sobre una zona de predominio indoeuropeo se fue extendiendo calmosamente una capa de población euskera. Probablemente, en época anterior a la que los trabajos de Schulten y Sánchez Albornoz daban a entender. Por ello, tal vez, y como reconoció finalmente el segundo, cuando, entre los siglos VI y VII, los vascones vasconizan la depresión vasca lo que hacen es reforzar, desde un punto de vista sociopolítico, lo que, desde el lingüístico, se detecta con anterioridad.

A tenor de todos los autores, cuando Alfonso I concluye sus correrías a mediados del siglo VIII, las cosas están ya lo suficientemente estabilizadas. Pero, desde nuestras preocupaciones por la percepción del espacio, diría que las seguridades no son tantas. De hecho, sigue en pie una cuestión sobre la que toponimistas e historiadores de la zona deberíamos indagar. ¿Cuáles son las dimensiones del espacio bautizado mayoritariamente por topónimos de origen indoeuropeo, ibérico, euskérico o romance en nuestra área norteña? Dentro de la pregunta incluyo dos series de cuestiones. Una, de densidad, esto es, de averiguación de las áreas en que son dominantes los topónimos de uno $u$ otro origen, y la proporción en que resultan hegemónicos respecto a otros. Como sabemos, y a propósito de la división espacial de los dominios del latín o del romance y del euskera, el tipo de estudio más comúnmente efectuado por los filólogos ha tendido a señalar el área vascoparlante en sucesivas etapas históricas. A partir de sus trabajos, es visible cómo, en época medieval, la frontera entre castellano y euskera, fijada en el Nervión, coincide con una división entre obispados. Pero, también, cómo este tipo de división eclesiástica se superpone a la de las grandes variedades del euskera: vizcaíno, al oeste del río Deva, obispado de Álava, más tarde, de Calahorra; guipozcoano al este de aquel río, obispado de Pamplona. Pero lo que planteo es algo más matizado. Dentro de esas áreas vascoparlantes, ¿cuáles son las áreas e intensidades de un bilingüismo en época medieval? O cuando menos, ¿cuál es el reparto espacial de los topónimos de una y otra procedencia? Porque, sin salir de la orilla izquierda de la ría de Mundaca, la toponimia nos habla de indoeuropeos (Guernica), de latinos (Forua), de euskaros (Busturia), de romances (Bermeo). 
Pero, a propósito de la toponimia, hay una segunda serie de cuestiones, más a tenor de estas preocupaciones por el espacio y el hombre medievales. Es el carácter que, desde el punto de vista de la organización social del territorio, tienen estos espacios bautizados por topónimos de distintos orígenes. En resumen, ¿abundan más los topónimos indoeuropeos o latinos para nombrar espacios que llamariamos territoriales, por ejemplo, los valles y alfoces a que aluden los falsos «Votos de San Millán»? ¿Se conservan, en cambio, los euskeras para espacios muy locales, como pequeñas barriadas y, sobre todo, caseríos? O, en otra jerarquía de percepción del espacio, ¿los nombres de las villas o núcleos urbanos son, mayoritariamente, romances? Sabemos que, en Álava, Guipúzcoa y Vizcaya, la fundación de las villas fue ocasión frecuente para que el fundador sustituyera, y a veces de forma deliberada, el nombre euskera de la aldea sobre que se asentaba la nueva fundación por otro de raigambre romance. Gamíniz-Plencia, Gasteiz-Vitoria, HagurainSalvatierra,... serían algunos de los ejemplos de una larga serie de casos que la actual política de recuperación del euskera ha llevado hasta los extremos de bautizar en vascuence muchos de los topónimos del área occidental de la actual provincia de Álava donde jamás se habló.

Denominación de espacios, socialización de espacios. Por ello, nos importa tanto una respuesta a esa serie de cuestiones. $Y$, por la misma razón, nos preocupa saber cuál es, en cada momento, el espacio abarcado por un determinado topónimo; o, sobre todo, por los corónimos que se reparten nuestra área de estudio. Y nos preocupa porque observamos en ellos una cierta movilidad. Más exactamente, una cierta expansión de los que acabarán imponiéndose. En ningún caso, esta expansión es tan espectacular como la que experimenta el nombre de Castilla, pero sí es perceptible en los casos de Guipúzcoa, Vizcaya y Álava. En los tres, desde una comarca muy concreta, el corónimo se extiende hasta abarcar, en la ségunda mitad del siglo XII, prácticamente, el territorio actual. Lo reconoce el escriba emilianense al redactar los «Votos de San Millán». Como siempre, la duda está, también a esta escala, en saber cuándo bautismo historiográfico coincide con nacimiento histórico. En cualquier caso, el análasis de la expansión documentada del vocablo "Álava» me permitió hace unos años proponer que el territorio denominado Álava es, precisamente, el área que van dominando los «alaveses». Y éstos, normalmente, los barones et milites alavenses, parece ya demostrado, son algo así como los cabezas de grupos extensos de parentesco. Donde florecen no arraiga la institución concejil como representación de la comunidad local. Ello diferenciará contundentemente dos zonas dentro de la actual provincia de Álava. Al este del Bayas y, sobre todo, del Zadorra, la tierra de los seniores et principes terrae al frente del populus. Al oeste, la tierra de los pe- 
queños concejos; dirigidos quizá, todavía en los siglos $\mathrm{X}$ y XI, por potestates familiares, ofrecen ya un testimonio de representación local de base territorial.

De esta constatación pueden deducirse, al menos, dos consecuencias significativas. De un lado, que la expansión de un nombre en un espacio traduce la expansión de un poder (¿político?) en ese mismo espacio. Vizcaya ofrecerá, a esos efectos, un ejemplo bastante definitivo. El corónimo parece referirse, inicialmente, a las tierras centrales del área que se extiende entre el Nervión y el Deva guipuzcoano. Desde allí, irá, poco a poco, irradiando, para englobar primero todas las tierras situadas entre ambos ríos; más tarde, las de Durango, que ofrecen particularidades expresadas, incluso, en algún ordenamiento jurídico propio; después, las de las Éncartaciones, área que, idiomática y eclesiásticamente, correspondía al ámbito castellanoviejo; y, por fin, Orduña y su valle. Pues bien, en todos los casos, es la existencia de un Señor de Vizcaya la que permitirá ir aglutinando, en torno a un núcleo central, esta diversidad de espacios menores. En última instancia, la pervivencia histórica de Vizcaya tal como ha llegado hasta aquí depende, por tanto, de la pervivencia de un Señor de Vizcaya, esto es, de un proyecto político. Por el contrario, la falta de un nombre es, en cierto modo, la falta de un proyecto político. Tal sucedió en Cantabria, cuya personalidad está escondida tras la de las merindades que la constituyen.

La segunda consecuencia a deducir del reparto sociopolítico de nuestra área norteña puede ser más discutible. Pero, en principio, hay que enunciarla. Por si acaso, lo haremos en forma de pregunta: ¿la división que, a la altura de los años 1050-1100, se observa entre los espacios en que domina una representación política de base familiar y espacios en que es característica ya una representación de base territorial corresponde a la que puede establecerse entre territorios repoblados por Alfonso I y territorios siempre poseidos por sus habitantes? En una visión rápida y simplificadora, y basada exclusivamente en el caso alavés, ésa podría ser la conclusión. Pero, si examinamos atentamente el comportamiento de Trasmiera, espacio repoblado por el monarca asturiano, observaremos que es el mismo que el de Vizcaya, Áyala o Álava. También en ella los grupos familiares extensos se constituyen en vehículos de representación de los intereses de la comunidad, dejando escaso o nulo protagonismo a las comunidades locales de base territorial, las aldeas. Por el contrario, las tierras de la primitiva Castilla, fronterizas con las alavesas, vizcaínas o trasmeranas, desde muy tempranamente dejan ver la fortaleza, incluso política, de las familias nucleares agrupadas en sus precoces concilia. La observación tiene algo de perturbadora. Vendría a decir que, pese a la presunta despoblación y repoblación de espacios como el valle del 
Duero o como las tierras de la Castilla primitiva y la Cantabria, hacia el siglo $\mathrm{XI}$, la documentación volvía a dar cuenta de una división socioespacial que recordaba mucho a la que describieron los geógrafos romanos. Un norte cantábrico arcaico; una meseta aculturada en su más amplio sentido. Pero ¿ello mismo no empuja a poner sordina a los efectos tanto de la despoblación de la meseta por parte de Alfonso I como a la repoblación de los valles cantábricos por sus gentes en el siglo VIII?

La exploración de las diversidades del espacio norteño ha permitido sacar a relucir unas cuantas. Basten ellas para subrayar su casi infinita variedad. Esta arranca desde bases biológicas. Sin exagerarlas, recordemos algo que nuestos antepasados medievales desconocían. La población vasca ofrece, en Europa, uno de los más altos porcentajes de individuos de Rh negativo. Aún en mantillas, la paleopatología comienza a relacionar hematología e incidencia de pestes y epidemias. Pero vayamos a aspectos mejor documentados. $Y$ si, de los testimonios escritos u orales, pasamos a los materiales, que todavía podemos captar en el terreno, nuevas certidumbres de variedad. En la tipología arquitectónica, por ejemplo, cuatro modelos fundamentales se esparcen por estas tierras. La casa montañesa, de dos pisos y amplia solana que mira al sur; la cabaña pasiega, vivienda eventual de la comunidad de ganaderos de los valles en sus estancias estivales en los pastos de altura, que, geográficamente, desborda por tierras de Espinosa de los Monteros, en la Castilla primitiva. Y las dos variedades de caserío vasco. La cuadrada y maciza, reminiscencia de época de banderías bajomedievales, pero también, funcionalmente, en relación con explotaciones familiares de intereses cerealistas. Y la alargada que parece la proyección de un triángulo, y que, funcionalmente, debió ser la traducción a vivienda de una primitiva cabaña ganadera. Sin un análisis exhaustivo de sus áreas de difusión y de la relación que media entre el nombre de cada caserío y su, tipología arquitectónica, no es fácil ir más allá de hacer ver esa variedad, de la que no sería difícil trazar una cartografía.

Esa misma diversidad sale a nuestro encuentro cuando nos detenemos en la morfología de los núcleos de poblamiento. Tres modelos, igualmente documentados en la Edad Media, se reparten nuestro territorio. De mayor a menor densidad de vivienda y exigencia de sociabilidad: la aldea, el barrio, el caserío. La aldea muestra hoy una doble variedad. La aldea alavesa, de casas exentas pero sin huertos entre ellas, reunidas en torno a un único polo de atención, normalmente, la iglesia. La aldea lebaniega, también con una sola iglesia, pero, con frecuencia, dividida en dos o más barrios, muy próximos entre sí, pero diferenciables en el espacio a simple vista; constituidos por 


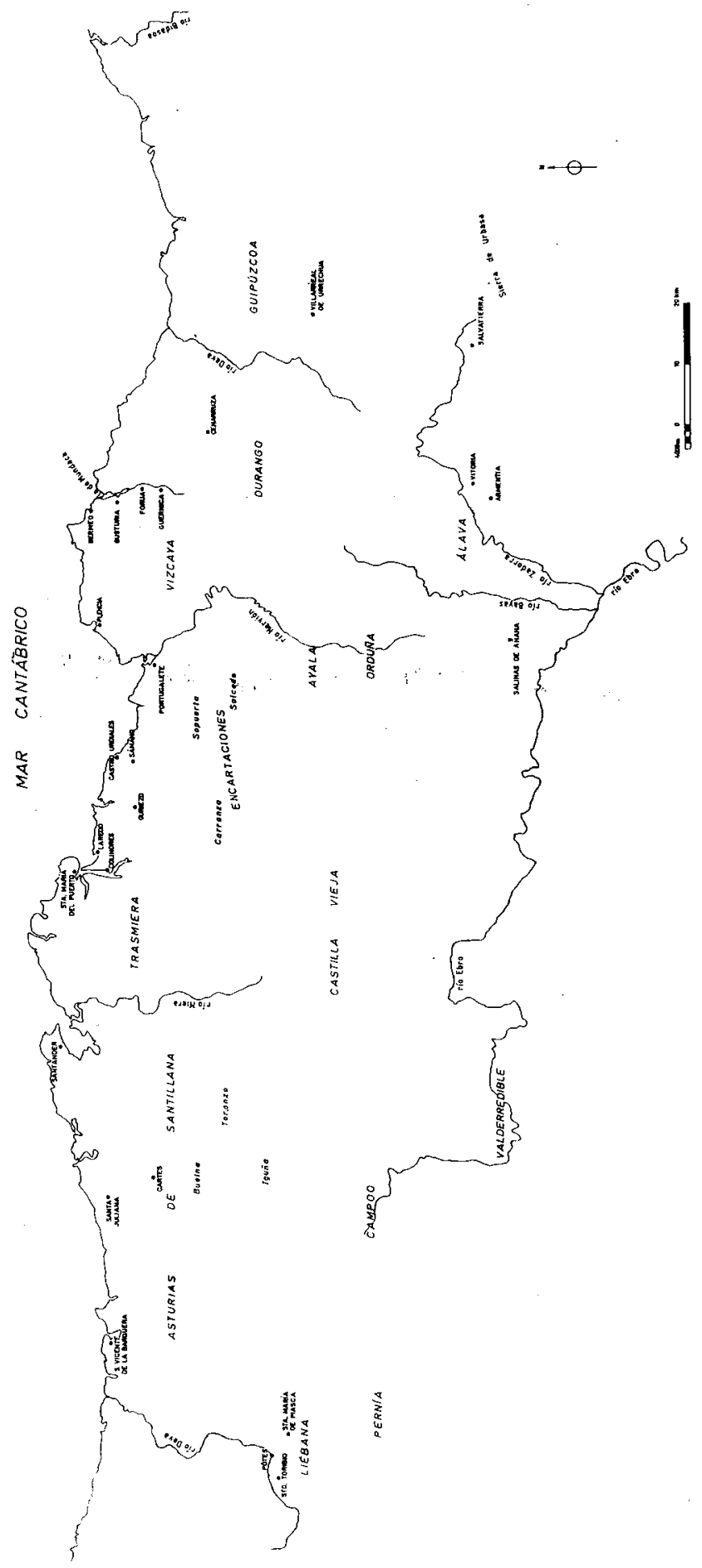


casas igualmente exentas, dejan a menudo entre ellas huertos y eras. El barrio también muestra una doble variedad bajo el denominador común de un reducido conjunto de viviendas agrupadas, sin aparente polo de nuclearización. En ocasiones, una pequeña ermita puede servir de ello. La primera variedad sería la del barrio trasmerano: en él, tres o cuatro casas se hallan adosadas compartiendo paredes medianeras y una misma orientación, que viene subrayada, visualmente, por la secuencia abalconada de las solanas. La segunda, la de la barriada vizcaína o guipuzcoana: el mismo número de casas que los barrios de Trasmiera, pero ya no adosadas, sino exentas; cada una, en edificación separada, con un cobertizo, resto, transformado, del antiguo garaixe u hórreo, y su horno; cada una con su nombre propio, por el que, más que por el apellido, serán conocidos los hombres y las mujeres que la habiten.

Por fin, el caserío morfológicamente individualizado, disperso en tierras de Guipúzcoa y Vizcaya, con un origen frecuente en seles o espacios de pastos altos acotados según medidas precisas. Su aparición histórica coincide con épocas de expansión demográfica dentro de una sociedad con un sistema de transmisión de la herencia que privilegia la trasferencia íntegra del patrimonio raíz familiar en beneficio de un solo heredero. De ahí que los siglos $X V$ y XVI y, más tarde, el XVIII, hayan visto nacer un buen número de los caseríos que hoy se desparraman por los montes vascos. La demostración de la secuencia bosque roturado-sel de pasto-sel de cultivo-cabaña estacionalcaserío permanente puede rastrearse a través de los contratos que se conservan de la Colegiata vizcaína de Cenarruza del siglo XV.

En definitiva, variedad biológica, variedad idiomática, variedad administrativa, variedad arquitectónica, variedad en la morfología del hábitat y del terrazgo y, progresivamente, variedad en las dedicaciones económicas. Ganadería de la vertiente norte de la Cordillera Cantábrica, cereal y viñedo de la sur; pero, más tarde, también, comercio y ferrerías del norte frente a actividad agrícola del sur. En todos los casos, una cierta compensación entre los distintos espacios bioclimáticos, pero, también, un distinto ritmo de desarrollo histórico. Porque si las variedades son tan abundantes como he apuntado, rara vez los rasgos diferenciadores se superponen delimitando con precisión los diferentes espacios. Más bien, según los criterios clasificatorios que empleemos, dos o más espacios aparecerán unidos dando una única imagen. Pero no serán siempre los mismos. Ello quiere decir que sus variedades son, en parte, producto de una geografía, pero, sobre todo, consecuencia de una historia. 


\section{ARTICULACIÓN: LOS INSTRUMENTOS DE ORDENACIÓN DEL ESPACIO NORTEÑO}

El área de difusión de una variedad lingüística, de un modelo arquitectónico, de un tipo de hábitat; la circunscripción de un obispado, de un alfoz, de una merindad constituyen dos de las modalidades del encuentro entre el hombre y el espacio. En la primera, parecen primar los aspectos meramente antropológicos de la relación; hay una acomodación al medio caracterizada por un alto grado de espontaneidad. En el segundo, parecen (y aquí, más que antes, subrayo el parecen) primar los aspectos políticos de la relación; hay una deliberada voluntad de limitar el espacio, de ordenarlo, independientemente de que, en aras del éxito, el poder ordenante se apoye en rasgos adquiridos por el espacio en la fase de presunta relación espontánea entre él y el hombre. El dibujo de las circunscripciones eclesiásticas en los siglos $X$ y $\mathrm{XI}$ sobre las fronteras de los pueblos prerromanos es un buen ejemplo de ello. Con menor conocimiento de causa, podríamos suponer que algo semejante ocurre con la división territorial de Álava en una serie de veinte circunscripciones, cada una de las cuales tiene un desigual número de aldeas y unos ciertos rasgos diferenciales. Es la imagen que ofrece un documento de 1025 conocido con el nombre de la Reja de San Millán.

En los dos casos, hay una ordenación del espacio. En el primero, su instrumento ha sido la autoridad eclesiástica que, en una etapa de fortaleceimiento de la Iglesia secular y en un deseo de precisar con seguiridad los límites de los espacios de percepción del diezmo, traza con rigor sus fronteras entre las distintas diócesis. Para hacerlo, aprovecha tradiciones espaciales anteriores. En el segundo, y dada la secular pervivencia de esa división territorial de Álava, podemos aventurar que, en origen, cada una de las veinte circunscripciones podría responder al espacio de dominio de un grupo de parentesco. Su fijación más estable acabaría conformando las diferentes aldeas de cada división. La hipótesis parece razonable si recordamos que, en Guipúzcoa y, sobre todo, Vizcaya, todavía en el siglo XV, los espacios comarcales aparecen claramente adscritos a ciertos linajes. Sus jefes, como se quejaban los obispos en las Cortes de Guadalajara de 1390, continuaban entonces percibiendo los diezmos de unas iglesias que estaban actuando como lentísimos polos de aglutinación del poblamiento en reducidos núcleos. Pero, como reclaman los obispos, hasta estas iglesias, ya parroquiales en sus funciones, siguen siendo denominadas monasterios por sus patronos en un intento de escapar, por esta vía, de la jurisdicción episcopal.

De este modo, fracciones gentilicias, o, más adelante, grupos de parentesco o de linaje y obispados son dos de los instrumentos de ordenación del 
espacio norteño. Aunque, en relación con un sistema cultural, unos y otros se hallan en sus antípodas respectivas, es curioso que los segundos adopten las mismas líneas de ordenación del espacio que los primeros. Son, probablemente, las consagradas por una vieja relación de transhumancia. Su extremo septentrional es siempre la franja costera cántabrovasca. Su extremo meridional varía. Puede ser la Sierra de Urbasa para los guipuzcoanos; la vertiente norte de la Sierra de la Demanda y alto Oja para los vizcaínos y alaveses; la vertiente sur de esa misma Sierra para las gentes de las Encartaciones, Ayala y la primitiva Castilla; y los macizos del Sistema Ibérico entre los cursos altos del Arlanza y el Duero para los trasmeranos y, sobre todo, los habitantes de las Asturias de Santillana. La disposición meridiana de las fortunas de los grandes monasterios de Oña y San Millán de la Cogolla, la política y geografía de las afiliaciones monásticas, el área de dominio de la familia de los Señores de Vizcaya, las concesiones de derechos de pasto en beneficio del Infantado de Covarrubias a fines del Siglo $X$,... todo ello induce a pensar en unas relaciones trazadas y mantenidas en función de precisos intereses de una ganadería extensiva. El hecho de que las primeras donaciones que recibe el monasterio de San Millán en territorio vizcaíno empalmen las que poseía antes en el alavés y, unas y otras, aparezcan instaladas, en el sentido de los meridianos, en un área que corresponde a una única variedad dialectal del euskera vizcaíno parece confirmar la verosimilitud de nuestro planteamiento.

Como se ve, entre los grupos de parentesco y los obispos, una variada gama de instrumentos trata de articular los espacios norteños. Por supuesto, la autoridad real. $\mathrm{O}$, mejor dicho, las autoridades reales, ya que, en especial, el área vasca de nuestro espacio norteño oscilará, entre los años 920 y 1200 , entre los reinos de Navarra y Castilla. Con todo, el papel directo de los monarcas como ordenadores del espacio, al menos, hasta fines del siglo XII, será muy limitado. Se sobreimpondrán a él pero respetarán en líneas generales su ordenación. Por ello, para localizar los ordenadores más eficaces y directos del espacio norteño medieval, hay que volver la vista a otros tres protagonistas. Los monasterios, las villas, la nobleza regional. $Y$, de entrada, podríamos anticipar que la fuerza respectiva de cada uno de los tres depende de la que muestren los otros dos protagonistas en liza. En general, será variable según espacios y cronología.

Los monasterios. De guiarnos por la nomenclatura, aparecen en toda la zona en estudio una multitud. Las quejas de los obispos en 1390 nos han alertado ya sobre la necesidad de matizar el valor de los vocablos. En efecto, muchos de esos monasterios son simples iglesias propias; otros se han con- 
vertido ya, en el siglo XIV, en iglesias parroquiales. Si eliminamos unos y otros, el número de los que, realmente, sirven de asiento a una comunidad monástica o canonical se ve drásticamente reducido. Con esas características apenas quedaría ninguno en Guipúzcoa, uno en Vizcaya (la colegiata de Cenarruza), otro en Álava (la colegial de Armentia, resto de la sede espiscopal alavesa, una vez que su capital se trasfiere a Calahorra) y cuatro en las merindades cántabras: Santo Toribio y Santa María de Piasca en Liébana, Santa Juliana en las Asturias de Santillana, Santa María del Puerto en la Trasmiera. Son sólo estas seis instituciones las que han dejado huellas documentales de su quehacer; y de ellas, únicamente, de las cuatro últimas puede seguirse con cierta seguridad su papel como verdaderos ordenadores del espacio.

Los mecanismos de que se valieron han sido ya objeto de estudio y responden a una dinámica general de la historia del Occidente europeo. Su desenlace será la sobreimposición de unas estructuras feudales sobre el mundo de las aldeas, cuyos habitantes entrarán en una dependencia cada vez más clara con respecto a las instituciones monásticas. En ese papel, los monasterios, a veces, no hacen sino recoger la herencia de poder y fortuna de algunas de las familias más aculturadas de cada comarca. La idea merece la pena subrayarse. $Y$, junto a ella, otras dos. Una, la de que los cuatro monasterios del área cántabra actuarán, desde que hay noticia de ellos, en los siglos IX y X, como deliberados instrumentos de aculturación de signo mediterráneo en un espacio de tradiciones primitivas más que propiamente germánicas. El mensaje que, a través de mil caminos, tratan de imponer a la población de la zona es la superioridad del cereal, del culto católico, de la familia nuclear, del reparto individualizado de los espacios de producción. De esa forma, los cuatro monasterios actúan como verdaderos propagadores de esas nuevas formas históricas. La resistencia que, en Trasmiera, oponen los infanzones «malvados» a los intentos del de Santa María del Puerto de Santoña es buen ejemplo del sentido de los intereses monásticos. La ruptura de unas estructuras tradicionales. La segunda idea a retener es que el mapa de las posesiones de los cuatro monasterios de la zona cántabra, a la altura del año 1200 , presenta unos límites que se corresponden, prácticamente, con las actuales fronteras de la comunidad autónoma. Ello reitera una imagen espacial que ya expresaba claramente la Crónica de Alfonso III: la personalidad de las comarcas de Liébana, Asturias de Santillana y Trasmiera. Desde el punto de vista de los domicios monásticos, la primera es el área de expansión de Santa María de Piasca y Santo Toribio de Liébana; la segunda, la de la colegial de Santa Juliana; y la tercera, la de Santa María del Puerto. 
En los tres casos, la dinámica de expansión y, por tanto, de ordenación del espacio por parte de estos monasterios tiene un desenlace altamente significativo de lo que será la historia posterior de esta área cántabra. En efecto, en-1052, Santa María del Puerto se convierte en dependencia del monasterio riojano de Santa María de Nájera. A fines del siglo XII, les tocará el turno a Santo Toribio de Liébana, convertido en priorato del monasterio de Oña, y Santa María de Piasca, integrado en el dominio del no menos poderoso de Sahagún. Desde ahora, sólo la colegial de Santa Juliana mantendrá su independiencia. En esos momentos, en que, simultáneamente, alumbraban las primeras villas de la costa, no se podía saber. Hoy, sí: la pérdida de independiencia de tres de los cuatro monasterios más significativos de la región de Cantabria era el síntoma de lo que será uno de los rasgos históricos más permanentes de la misma. La excentricidad respecto a los centros de toma de decisiones que la afectan. Al constatarlo, las generosas concesiones de pastos que, en favor del infantado de Covarrubias y del monasterio de Oña, habian hecho, a fines del $\mathrm{X}$ y comienzos del XI, los condes de Castilla, adquirian el tono de premonición. Cantabria como periferia ganadera de un centro cerealista situado en Castilla.

Segundo factor ordenador del espacio, las villas. En el área cántabrovascongada, la primera creación tiene lugar en 1140 y corresponde a la hoy alavesa Salinas de Añana; la última, en 1383, a la guipuzcoana Villarreal de Urrechua. En medio de una y otra, 72 , lo que hace un total de setenta y cuatro fundaciones repartidas en un territorio de 12.000 kilómetros cuadrados. Una simple ojeada al mapa nos mostraría lo desigual de tal reparto. Una cronología de los nuevos villazgos confirmaría, también en el tiempo, y, por tanto, en la coyuntura histórica, la misma desigualdad. Ambos procesos han sido ya analizados en otras ocasiones, y las conclusiones llaman la atención sobre un hecho aparentemente sorprendente. Veinticinco villas se fundan en Guipúzcoa, veintitrés en Álava, veintiuna en Vizcaya y tan sólo cinco en Cantabria, pese a que este territorio dobla en extensión a cada uno de los otros por separado. De la constatación no parece arriesgado deducir dos corolarios. Uno, a mayor protagonismo de los monasterios en la primera fase de la ordenación del territorio, menor protagonismo de las villas en la segunda. La aseveración cobra todo su valor cuando observamos que, de las cinco villas cántabras, dos han nacido en y por los dominios monásticos existentes: Santillana, Santander, y, con ocasión de la fundación de las otras tres, el monarca, siempre el mismo en las cinco ocasiones, Alfonso VIII de Castilla, ha debido pactar con los poderes monásticos o nobiliares de la zona para adquirir el terreno en que alzar la nueva puebla. El segundo corolario es todavía más evidente: el territorio vascongado debe, históricamente, su ordenación 
a las 69 villas creadas en él. Y la afirmación conserva su validez hasta nuestros días.

Con todo, habría que matizarla desde un principio. Una villa, en efecto, nace en una coyuntura histórica determinada. Puede, por ello, ser hija del estímulo mercantil, como, en general, las creadas en nuestra zona entre 1140 y 1330 . Pero, también, una villa puede ser hija de una deliberada voluntad de reordenación social del territorio y ello fue así en las villas creadas entre esa fecha y 1383. En todos los casos, no hay que olvidar que alguien con facultades para hacerlo ha tomado la decisión de crear una nueva puebla o de reconvertir en villa una vieja puebla. En Vizcaya, salvo en los casos de Valmaseda y Orduña, siempre el señor. En Cantabria, Álava y Guipúzcoa, siempre el rey. Esto convierte a las villas en un instrumento deliberado de ordenación del espacio en manos del rey o del señor de Vizcaya. Ellos tienen obligación de «acrescentar siempre sus señoríos ... (lo cual se hace ganando e cobrando) la tierra de los enemigos ... y de defender e amparar e juntar lo que esta ganado ... (lo cual) se faze faciendo e ordenando ciudades e villas cercadas e castillos e otras fortalezas do puedan los homes vivir vienaventuradamente e seguros». Por ello, hay que enmendar un tipo de poblamiento disperso, como es tan característico de estas tierras norteñas; hay que concentrar población. Hay que ordenar el espacio.

En el caso de los monasterios, la ordenación aparecía como un resultado. En el caso de las villas, la ordenación es una premisa. Una premisa que afecta de puertas afuera de la villa, pero, antes, de puertas adentro de la misma. En efecto, la morfología de las villas norteñas, en especial, vascongadas, deja ver claramente la voluntad de ordenación urbanistica que, desde el punto de vista arquitectónico, preside su fundación. Dos, tres, cuatro y hasta siete calles paralelas, cortadas por cantones o callejones, reparten el caserío de casi todas estas villas en una red ortogonal. La formalización del plano y la rigurosa distribución del espacio intramuros en solares de idénticas dimensiones, con frecuencia, seis metros de ancho por doce de largo, proclama la ordenación de la vida colectiva desde el comienzo de la existencia de la nueva villa. Sólo con una aceptación unánime de las disposiciones constructivas puede erigirse en la forma y con la rapidez y regularidad con que se hicieron el conjunto de villas vascongadas. Rodeadas inicial o finalmente por una cerca, ésta separa visualmente el espacio urbano de la tierra llana aldeana. Como sabemos, algo más que visualmente. También desde el punto de vista económico, social y político, unas ciertas diferencias se establecen entre los núcleos murados y las aldeas. El disfrute de un mercado semanal y, eventualmente, de una feria anual, el reconocimiento de una cierta jurisdicción de 
las autoridades de la villa sobre el entorno rural de su término..., todo ello crea una jerarquía de intereses en el espacio. Las antiguas unidades homólogas, las aldeas, empiezan a ser subordinadas a esta naciente entidad.

La respuesta aldeana fue enormemente variada. En Álava, la incorporación de las aldeas al término de las villas más significativas se hizo por la vía de la compra por parte de los burgueses de Vitoria y Salvatierra. En Guipúzcoa, las villas consiguieron sustituir a los viejos "valles» y «tierras" en la tarea de aglutinar el poblamiento. Salvo un reducido espacio en el centro de la provincia, constituido por las alcaldías mayores de Arería, Sayaz y Aiztondo, el resto se repartió entre los términos de las veinticinco villas. Cada una de éstas pasó a ocupar la cabeza, en una especie de traducción «sui generis» de las comunidades de Villa y Tierra castellanas. Por fin, en Vizcaya, la historia fue más compleja. Las villas, al menos, las más poderosas, con la de Bilbao a la cabeza, tendieron a hacer una interpretación rigurosamente territorial de los párrafos de la carta-puebla en que se disponían los términos de cada viIla. De esa forma, donde el fundador habia respetado los diversos status sociales de los habitantes asentados en el término, muchos de ellos hidalgos, las autoridades bilbaínas, bermeanas o duranguesas, en especial, a fines del siglo $\mathrm{XV}$, sintieron tentaciones de desconocer ese respeto.

Según ellas, en la práctica, todo lo que estaba dentro de los límites fijados en la carta de población caía bajo su autoridad, fuera cual fuera el status sociojurídico de sus vecinos. La reacción de éstos, en especial, en el caso de lo que interpretaron como imperialismo bilbaíno, fue fulminante. En el año 1500 , los hidalgos de las anteiglesias del entorno llegaron a hacer triunfar su tesis de que la jurisdicción de Bilbao acababa en la sombra que proyectaba su cerca. Durante tres siglos y medio, a Bilbao sólo le quedó el consuelo de ejercer algunos gestos de autoridad en su entorno rural. Aunque pocos, fueron casi siempre recibidos con hostilidad por los hidalgos de las anteiglesias vecinas. Que éstos conservaran el fuero no debe hacer olvidar que la villa se alzó con el huevo de la ordenación del territorio.

Tercer protagonista de la articulación del espacio, la nobleza. Acabamos de ver a los hidalgos vizcaínos enfrentados a la villa de Bilbao. Poco antes, veíamos al Señor de Vizcaya como promotor de, al menos, dicienueve de las veintiuna villas del Señorío. $Y$, todavía antes, nos referiamos a la resistencia de los infanzones de Trasmiera a las pretensiones del monasterio de Santa María del Puerto de Santoña. En las tres ocasiones, miembros de la nobleza tomando postura beligerante en los problemas de ordenación del espacio. Lo mismo podríamos decir del primero de los nobles del reino, el propio mo- 
narca, inductor de la mayoría de las fundaciones de villas norteñas. De los cuatro ejemplos, es fácil deducir, con todo, dos actitudes claramente contrapuestas. Una a favor, otra en contra de esas creaciones urbanas que modificaban la composición de fuerzas sociales en un territorio dado. En general, puede decirse que la nobleza regional se opuso, en principio, a tal ordenación urbana porque tenía la suya propia. Así, puede verse con absoluta claridad en Álava y Vizcaya o en las merindades cántabras; sólo en Guipúzcoa la nobleza regional se mantuvo en una actitud menos belicosa. La razón hay que buscarla, sin duda, en el distinto tratamiento que el estatuto hidalgo iba a recibir en las villas recién creadas. En Vizcaya, se aspiraba a igualarlo con el de los restantes vecinos; un mismo territorio inducla un mismo status sociojurídico. En Guipúzcoa, en cambio, los hidalgos podían incorporarse a las villas en la seguridad de que su status iba a ser respetado. No había, por ello, razón para un enfrentamiento frontal a la nueva realidad urbana.

De hecho, tampoco la tuvieron los hidalgos vizcainos mientras la densidad demográfica del Señorío les permitió reproducir su modelo extensivo de organización del espacio. Basado en la ganadería, prácticamente, hasta fines del siglo XIII, no tuvo oposición alguna. Ello quería decir que los distintos grupos de linaje en que, en estas fechas, aparece dividida la sociedad rural vizcaína, tenian reconocidos, según áreas comarcales, unos derechos de aprovechamiento de pastos y montes. Ello permitirá la instalación más fija de los miembros del linaje en los caseríos de las distintas barriadas que surgen entonces y, más adelante, en los caseríos absolutamente individualizados y diseminados. Todo ello configura pequeños espacios de dominio de los diferentes grupos familiares. Las rivalidades banderizas de los siglos XIV y XV entre oñacinos y gamboínos los pondrán de manifiesto, permitiendo cartografiar en líneas generales las grandes manchas de los asentamientos de los linajes de uno y otro bando. Precisamente, una de las razones, y no la menor, de esos enfrentamientos banderizos fue, sin duda, la convicción de que el modelo extensivo de organización del espacio empezaba a chocar con otras realidades. Concretamente, con la de una progresiva territorialización de los intereses económicos y del poder político.

La territorialización del poder político la habian impulsado decididamente las villas desde su creación. Más aún, ellas representaban el trunfo de ese modelo con su tendencia a delimitar con claridad términos, jurisdicciones, status sociojurídicos dentro y fuera de un determinado espacio. En cierto modo, esa territorialización sirvió de pauta para que la organización del espacio de base familiar empezara a su vez a cobrar conciencia de la necesidad de territorializar y precisar sus ámbitos geográficos de competencias. A asimilar y 
estimular la nueve realidad contribuyeron los nuevos intereses económicos. Frente a una ganadería extensiva, para la que era casi igual el valor de cada uno de los espacios, aparece ahora, de un lado, un creciente interés cerealístico e incluso vitivinícola por parte de las familias instaladas en sus caseríos, $y$, por otro, sobre todo, una aceleración de los intercambios mercantiles, inducidos por las villas, y el despertar de una industria ferrona. A tenor de estos cambios, cada parcela del espacio adquiere un valor diferente. Proximidad - lejanía de una villa, de un puerto, de una encrucijada caminera; pero también derecho o no a participar en la explotación concreta de un monte más poblado de árboles o de un riachuelo de caudal más regular y seguro para mover los ingenios de las ferrerías que surgen por dóquier. Cada fragmento del espacio adquiere así un valor distinto.

Los nobles vizcaínos empezaron a ser conscientes de ello poco después de 1300 , precisamente, cuando las ferrerías alavesas perdian valor económico por la deforestación de los bosques. La carta-puebla de Portugalete muestra ya signos inequívocos de una tensión entre habitantes de las villas e hidalgos rurales por la instalación de las ferrerías. Veinte años más tarde, en 1342, los vizcaínos, para conocimiento de su señor Juan Núñez de Lara, ordenan en un capitulado las prácticas usuales en materia penal, pero aprovechan los últimos diez renglones para ponerse en guardia contra posibles intentos del Señor o de las villas de reducir los aprovechamientos de monte y bosque por parte de los hidalgos. El interés por la explotación del hierro es ya, para esos momentos, evidente. Ella dará nuevo sentido a la organización social del espacio propugnada por la nobleza regional. Al menos, en el caso de Vizcaya, que, en este sentido, acogerá a muchos de los linajes a los que la roturación de la Llanada alavesa y la deforestación de los bosques que la rodeaban ponía en dificultades. El clima más húmedo de Vizcaya y las posibilidades que ofrecía el comercio no pasaron desapercibidos para estos nobles de las tierras más altas de Álava. Alguno de ellos lo confesó paladinamente, reconociendo que su padre le había animado a emigrar hacia la costa, «donde no le faltaría con que amatar la gana de comer».

El interés por la producción del hierro, por los beneficios del comercio, por las rentas de los caseríos de nueva creación en espacios del linaje, por la percepción de los diezmos de las iglesias, todo ello contribuía a reorientar las modalidades de ordenación del espacio que, hasta entonces, habian escogido los nobles regionales y, en principio, a valorar aquél de forma más cuidadosa. Su respuesta, con todo, varió según los distintos territorios. En Guipúzcoa y Vizcaya tomó los derroteros de una incorporación más o menos convencida a las nuevas realidades del comercio y la industria del hierro. En Ála- 
va, se acercó igualmente a las villas, pero éstas, salvo Salinas de Añana, Vitoria y Salvatierra, no mostraban ya, desde mediados del siglo XIV, el dinamismo de sus compañeras de la costa. Por ello, para muchos nobles alaveses, sólo se abrió un modesto pasar, de base cerealera, a la sombra de algunos de los grandes linajes: los Ayala, Gamboa, Mendoza.

Por fin, en las merindades cántabras, pese a la proximidad de la costa, la respuesta se pareció un tanto a la alavesa. A la sombra de los grandes señores de la Vega, Castañeda, Santillana, el interés de los pequeños fue ampliar, a base de modelos ya ensayados desde muy antiguo, en especial, la presión fiscal y las exacciones sobre los campesinos, sus pilares de sustentación. Los pleitos que, a fines del siglo XV, se suscitan en los Nueve valles contra el marqués de Santillana recuerdan los que, desde fines del siglo $\mathrm{XI}$, al menos, habian expresado la resistencia campesina a la imposición feudal. Como dato complementario, los intereses exteriores de la más alta nobleza de origen alavés o cántabro se mostraban mucho más sólidos que los de los hidalgos vizcaínos o guipuzcoanos. También desde este punto de vista, mientras Guipúzcoa y Vizcaya se constituian en espacios económica y políticamente dotados de personalidad, de autosuficiencia decisoria, Álava y, sobre todo, las merindades cántabras volvían a evidenciar su engarce sociopolítico, esta vez, a través de los intereses de un reducido grupo de casas nobiliares, con espacios más meridionales. Como había sucedido con la primera ordenación espacial gestada por los monasterios, la nobleza cántabra iba, otra vez, a diseñar para la región un destino de periferia de sus intereses centrados prioritariamente en Castilla. La saga familiar de los marqueses de Santillana puede ser un paradigma. La de los Velasco, otro.

\section{JERARQUIZACIÓN: LA SECUENCIA HISTÓRICA DE LAS FORMAS DE ORGANIZACIÓN SOCIAL DEL ESPACIO NORTEÑO}

Monasterios, villas, nobles, desde diversos planteamientos y cronologias, habian actuado como ordenadores, como articuladores del espacio norteño. Al compás de su actuación, van tomando forma, y después fortaleza, unos cuantos espacios y, sobre todo, unas cuantas modalidades de percibir, de sentir, el espacio. Al final del recorrido, de una situación inicial de intercambio entre espacio natural y hombre, entre naturaleza y cultura, se ha pasado a otra en que el hombre ha puesto nombres a los espacios, los ha socializado y los ha ordenado, adquiriendo conciencia de su diversidad, de sus límites, de su valor. La sucesión de sentidos del vocablo euskaro ola puede simbolizar el proceso. En un primer momento, significó lugar en el sentido más vago de la expresión, esto es, sitio de algo. En un segundo, pasó a ser cabaña 
del ganado. $Y$, desde fines del siglo XIII, ferrería. La historia de los significados de una sola palabra ejemplificando la historia de los significados del espacio.

Al término del proceso, en el siglo XV, la configuración física de las villas cercadas por sus murallas, en claro contraste con el entorno rural sin ellas, constituía la imagen misma del final de la antigua situación de intercambios espontáneos entre naturaleza y hombre. Desde esas villas, a través de la difusión de sus medidas específicas, de Durango, de Cartes, de Santillana, de Potes; a través de su papel de motor de una actividad mercantil, estimuladora de los cambios monetarios, siempre escasos en el medio rural del área norteña, y de los circuitos de transporte entre localidades de la región o entre ésta y el exterior, el espacio físico va adquiriendo una precisa jerarquización. Pero lo mismo sucedía con el social; en Vizcaya, sobre todo, la fortaleza institucional de los linajes hidalgos, reforzada en su Fuero Viejo de 1452, llega a producir una verdadera división social del espacio: el villazgo de un lado, el infanzonazgo de otro. A la vez, se fortalecen los respectivos centros del espacio político de la comunidad hasta llegar a adquirir el valor de símbolos supremos de la misma. El árbol, en unos casos; el atrio del templo, en otros; la casa del concejo, más tardíamente, en los menos.

Árbol, atrio, casa. Árbol de Guernica, de Guerediaga, de Avellaneda; atrio de San Emeterio de Goicolegea, de Santa María de Galdácano, de San Pedro de Dima; casa del concejo de Bilbao, de Elgoibar, de Vitoria. La propia secuencia habla de dos procesos. El tránsito histórico de unas comunidades fundamentalmente ganaderas a otras con dedicaciones económicas más sedentarias será el primero. La evolución de una base numénica a otra cristianizada y, por fin, secularizada del poder sería el segundo. Junto a ellos, una observación que matiza los comportamientos en nuestro espacio norteño. La conservación del árbol como símbolo del centro del espacio político de la comunidad proclama el vigor que, todavía en la Vizcaya del siglo XV, tenía la representación a escala territorial en manos de los hidalgos. Para esas mismas fechas, las Juntas generales de Guipúzcoa se habían reunido ya con frecuencia en el coro de la iglesia de San Salvador de la villa de Guetaria. También desde ese punto de vista simbólico, parecía mantenerse una diferencia antes señalada: las villas guipuzcoanas habían conseguido integrar a los hidalgos en su red sociopolítica. Las villas vizcainas parecian arrinconadas tras sus cerca y una clara división del espacio social del Señorío era su resultado.

Ya hemos reiterado que no fue la única. El documento de los Reyes Católicos de 1480 con que comenzaba mi exposición dio cuenta de otras muchas más. En él el espacio era mirado con ojos de administrador, de poder 
político. Pero otro de los testimonios que situé en el pórtico de estas páginas hablaba de una distinta forma de ver el espacio. Me refiero al diploma de los falsos "Votos de San Millán", que subrayaba una secuencia de valles, alfoces, aldeas, casas. De mayor a menor dimensión, una escala de percepciones espaciales. pero, a la vez, una jerarquización de marcos de sociabilidad. En definitiva, sumando unas y otras, una serie de etapas de organización social de nuestro espacio. No voy a reiterar ideas que no hace mucho expuse por escrito y sobre las que seguimos investigando en Santander. Pero mi exposición quedaría incompleta si, al menos, a modo de conclusión, no recuerdo la hipótesis de engarce entre esos espacios captados por el monje emilianense de mediados del siglo XII.

El hilo conductor lo podemos situar en el proceso de aculturación de las comunidades ganaderas del Norte peninsular, que, a través de los estímulos y de los instrumentos puestos a disposición de sus jefes por parte del feudalismo, tienden a formas progresivamente más rigurosas, más individualizadas, de apropiación del espacio. A cada etapa significativa de ese proceso corresponde un marco característico de sociabilidad, con sus dimensiones espaciales y sus exigencias sociales. El primero, el valle o tierra, que, con frecuencia, aunque no siempre, tiene un valor morfológico desde el punto de vista físico, es el asiento de la comunidad rural constituida por una fracción coherente de un grupo étnico más amplio. Su percepción del espacio se basa en sus intereses ganaderos extensivos, y tiene una dimensión comarcal. Su representación política queda en mano de sus jefes familiares que, unidos a los de otros valles o tierras, asumen la autoridad de todo el conjunto $y$, por extensión, del espacio en que se asienta. El valle de Iguña en las Asturias de Santillana, el valle de Ayala en las tierras bajas, atlánticas, de Álava, serian buenos ejemplos de esta realidad. Su organización sociopolítica puede estudiarse aplicando el modelo bien conocido del Señorío de Vizcaya. Hasta fines del siglo $X V$, éste ofrece, a esos efectos, la imagen de organización territorial propia de un «valle» o de un conjunto de «valles». Ello quiere decir que, hasta esa fecha, al menos, la representatividad política estaba en manos de la nobleza rural, cada uno de cuyos miembros más relevantes, los parientes mayores, actuaba como cabeza de un grupo de emparentados claramente jerarquizado.

El segundo marco socioespacial percibido por el monje emilianense es el alfoz. Para él, suponía una circunscripción fraccionada del valle, en torno a un polo de nuclearización, y con límites mejor conocidos que los del valle; tal vez, porque eran más recientes y, también, más deliberadamente puestos por los hombres. En nuestro espacio norteño, el vocablo alfoz vendrá a bauti- 
zar lo que, en seguida, va a ser la parroquia. Su población daba muestras de un mayor grado de instalación fija en el territorio; precisamente, en función de una dedicación agrícola de carácter estable, basada, sobre todo, en el cereal. Ello favorecía, o, mejor, reclamaba la instalación de grupos familiares de menor tamaño esparcidos por el amplio espacio del alfoz y del valle para atacar, desde distintos puntos, la masa arbórea en medio de la cual aparecian inicialmente perdidos. Con frecuencia, el polo nuclear de sociabilidad lo constituye un templo, en manos de los monasterios regionales en Cantabria o de los parientes mayores en Vizcaya y Guipúzcoa. Los mensajes expresos y simbólicos de superioridad de cereal y viñedo, de familia nuclear y de capacidad individual de disponer de fracciones del espacio, que, desde esos templos, se emitieron, contribuyeron, sin duda, a acelerar, más en Álava y Cantabria que en Vizcaya y Guipúzcoa, una percepción del espacio a la escala de esta dimensión más reducida. La cristalización de la red parroquial, enormemente lenta en estas tierras, en especial, las vizcaínas, marcaría, en cada caso, el ritmo del proceso.

La cristalización de la red parroquial significaba otras cosas. Una de ellas que, por encima del conjunto de pequeñas ermitas, iglesias y monasterios de la primera hora, uno de los templos erigidos en el espacio ocupado por la comunidad rural del alfoz se convertía en núcleo sociorreligioso del conjunto al que quedaría subordinado el resto de las pequeñas células religiosas existentes. Ello permitia trazar la reticula parroquial. Con frecuencia, le correspondió otra de carácter sociopolítico: una de las modalidades del concejo rural venía a coincidir, en efecto, con las dimensiones de la parroquia, esto es, con el marco socioespacial que creemos que el monje emilianense hacia equivalente al alfoz. Pero este último incluía otros marcos de sociabilidad de menor tamaño, las aldeas.

Con o sin iglesia que fuera su eje de cristalización social, las aldeas aparecian como las unidades básicas de la red de poblamiento y un paso más avanzado en el proceso de apropiación del espacio. Con un sentido territorial mucho más arraigado, aldeas, barrios, barriadas o ledanías, según las áreas, constituyen una célula de organización deliberada de los aprovechamientos del espacio. No se trata ya de una percepción del espacio desde fuera del mismo o desde los usos extensivos del ganado. Se trata de un esquema de integración de tres elementos: un grupo humano, un espacio de aprovechamiento económico claramente delimitado física y socialmente y un conjunto de relaciones entre el primero y el segundo. Implica siempre un alto grado de territorialidad, aunque sus niveles variaron en la época medieval en nuestra zona. En general, lo que los textos evidencian es una tendencia a la diso- 
ciación, aquí siempre muy imcompleta, entre espacios de habitación, de cultivo y de aprovechamiento ganadero. El reducidísimo tamaño de la mayoría de las aldeas norteñas deja esa tendencia en el nivel de hipótesis conveniente al modelo, aunque los datos existentes permiten comprobarla en Liébana y Álava. Como grupo humano, aunque pequeño, la aldea ofrece también un embrión de representación política que, por sus propias dimensiones, acaba siempre oscurecido en nuestros textos por el concejo del conjunto de la parroquia o, en Vizcaya, de la anteiglesia.

Desde el punto de vista de las relaciones entre espacio y hombre, la aldea norteña es un producto que parece derivar naturalmente de la progresiva reducción del tamaño de las estructuras familiares en función de una dedicación económica más productiva y más valorada de las distintas fracciones del espacio. Pero no hay que olvidar que esa misma aldea, en cuanto reunión de grupos familiares de carácter nuclear copartícipes de un espacio, resulta, en gran medida, producto de una deliberada política señorial. La que propende a fortalecer los rasgos, los perfiles del cuarto marco socioespacial, el solar familiar. Frente a la indefinición del espacio del valle, la rigurosa definición territorial, pero también personal, del solar como medida del esfuerzo de producción, de aportación de trabajo al señor o de rendición de cuentas de una fiscalidad. El solar, la casa, el caserío se convierte así, como reitera machaconamente el documento de los Votos de San Millán, en la célula fundamental del sistema y, según aquél, aparece, precisamente, en los espacios más aculturados. Por ello, no lo menciona en Guipúzcoa y Vizcaya. Pero fuera de ellas, por todas partes, omnes domus son las requeridas para pagar el censo al santo. Todas las casas, cada casa, es la cantinela de cualquier contrato agrario desde mediados del siglo XII. Y a perfilar sus dimensiones y sus facultades sí contribuyó decisivamente el pọder feudal.

En un sistema que aspiraba a obtener rentas, fundamentalmente, de la tierra, la existencia de casas y solares poblados era, en definitiva, la garantía de que los campos se labraban, las viñas se cultivaban, los ganados se cuidaban y las prestaciones se efectuaban según una medida. La cristalización del solar familiar, del domicilio fiscal fue, en el Norte peninsular, como en otras regiones europeas, el éxito final del proceso de feudalización. Agrupado en barrios y aldeas, o absolutamente diseminado, el solar familiar se instaura como la medida de todos los esfuerzos en la relación entre el hombre y la naturaleza. Las obligaciones hacia - y el sentido de - la comunidad serán muy diferentes según esos modelos de caseríos, pero, en los dos, se habrá afianzado vigorosamente la idea de la necesidad de una transmisión intacta del patrimonio familiar. 
Como sabemos, su individualización en forma de solares y caseríos rurales fue uno de los desenlaces posibles de nuestra historia. El otro, hoy tan visible como el anterior, fue el de la agrupación voluntaria, deliberada, de estas familias, de estos solares, en forma de villa, de ciudad. Parecía como si a la disgregación final de las viejas comunidades rurales de valle, la nueva realidad física y social de las villas ofreciera una compensación. La de una asociación de esos mismos troncos familiares ahora ya reducidos a su expresión conyugal nuclear. Pero una asociación en términos de aparente igualdad sociojurídica, de deseada igualdad de base territorial. Por los dos lados, el del caserío y el de la villa, un único final: territorialización económica, individualización social. Los dos necesitaban la existencia de una célula pequeña, manejable, desasida de otros vínculos más extensos. El caserío para incorporar nuevos espacios marginales a la realidad del cereal o de la ganadería estante; la villa para reunir, en una morfología geométrica, racional, aparentemente ajena de la vieja concepción antropológica del valle, a los solares familiares. En definitiva, por todas partes, en todos los escenarios, desde fines del siglo XII y de forma progresivamente acelerada en toda la España norteña, la comunidad familiar de casa se aprestaba a constituirse en la nueva y fundamental unidad de relación entre espacio y hombre.

* El presente texto constituyó, en su momento, la ponencia que su autor presentó a la «XVI Semana Internacional de Estudios Medievales", celebrada en Barcelona en junio de 1986 sobre el tema El espacio y el hombre en la Edad Media. Lo acompaña un mapa que recoge la toponimia mencionada en el texto y que ha sido elaborado por Esther Peña Bocos, colaboradora en las tareas de investigación. 